\title{
A Study to Compare the Knowledge of Hand Hygiene among Nurses in a Public Tertiary-Care and a Private Corporate Hospital in Amritsar
}

\author{
Vardeep Singh Dhillon (B.D.S., M.H.A., P.G.D.H.P) \\ Assistant Professor (Hospital Administration), Department of Sports Medicine and Physiotherapy, Guru Nanak Dev University, Amritsar \\ (Punjab), India
}

\begin{abstract}
Background: Hand hygiene is a simple, cost-effective way to reduce nosocomial infections, but the compliance with hand hygiene remains low. Nurses, due to the nature of their work, spend maximum time with the patients and therefore have higher number of opportunities to transmit infections from one patient to another. Material and method: A cross-sectional survey was conducted using World Health Organization's 'Hand Hygiene Knowledge Questionnaire for Health Care Workers'. Data obtained from the questionnaires was analyzed using descriptive statistics, and Pearson chi-Square Test. Results: there were significant gaps in the knowledge of nurses with respect to the various aspects of hand hygiene. 50\% of the nurses in the public hospital had not received any hand hygiene training in the past three years. Less than $30 \%$ of the public-sector nurses knew that unclean hands were the main route of cross-transmission, more than $50 \%$ of the respondents were not aware of the primary source of germs and the correct time duration for the use of handrub. $79 \%$ nurses in the private hospital had no idea that handrubbing is more effective against germs than handwashing. Conclusion: Implementation of need-based education and training programmes, along with other elements of WHOs 'multimodal strategy' is required to improve the knowledge and change the behavior of nurses.
\end{abstract}

Keywords: nosocomial infections, hand hygiene, knowledge, gaps, education

\section{Introduction}

Hand hygiene has been recognized as one of the most simple and cost effective ways to reduce the incidence of health care associated infections (HCAIs) ${ }^{1-3}$. In spite of being a relatively uncomplicated procedure about 40 percent of the health care workers do not comply with the established protocols for hand hygiene ${ }^{4-6}$. The importance of hand hygiene was established as early as the middle of the nineteenth century by pioneers like Ignaz F. Semmelweis and Florence Nightingale?

The prevalence of HCAIs in developing countries is as high as 15.5 percent and about 7 percent in high-income countries ${ }^{8}$. HCAIs lead to increased mortality and morbidity, prolonged hospital stay, additional pain and suffering, increased cost of treatment, resistance to antimicrobials, and an additional burden on an already strained healthcare system ${ }^{9}$. Baker et al have suggested that 37 percent of HCAI are preventable ${ }^{10}$ and the United Kingdom Department of Health reported that 10 percent of HCAIs are directly related to non-compliance or low compliance with hand hygiene guidelines ${ }^{11}$.

Performing proper hand hygiene is the easiest and most effective way to reduce HCAIs ${ }^{12}$ and according to Stone et al. it involves the appropriate use and accessibility of alcohol rubs and soap ${ }^{13}$.

Nurses are the most numerous among different categories of health care workers ${ }^{14}$ and they play a central role in any healthcare system ${ }^{15}$. The four main tenets of nursing recognized all over the world "to promote health, to prevent illness, restore health and alleviate suffering" emphasize the importance of a nurse ${ }^{e s}$ job ${ }^{16}$. Nurses spend maximum time with the patients and nature of their work is such that they have the highest number of opportunities to transmit infection from one patient to another. Therefore, it becomes imperative for the nurses to perform correct hand hygiene and prevent HCAIs.

It is important to educate health care workers about hand hygiene and its benefits but it is equally important to identify and explore the reasons why hand hygiene is not followed $^{12}$. Non-compliance may be due to a variety of reasons, including: lack of appropriate facilities for hand washing, high staff-to-patient ratios, insufficient knowledge and attitudes of the staff, and allergies to hand washing products $^{17}$.A plethora of interventions have been suggested to improve compliance, they include both, single and multimodal interventions - increase in the availability of spaces where hand hygiene can be performed ${ }^{18}$, staff education and training, prompts and reminders, monitoring and feedback, cultural change and patient engagement.

\section{Material and Methods}

Study Design: A descriptive, cross-sectional survey design was implemented in which data was collected by means of a self-administered questionnaire (The World Health Organization"s „Hand Hygiene Knowledge Questionnaire for Health Care Workerse')

Setting: This study was conducted at a government and private, super-specialty healthcare facilities with more than 150 beds.

Inclusion criteria: Individuals were eligible to participate if they fulfilled the following inclusion criteria:i) worked as a registered nurse/ student nurse; ii) Provided direct patient care; andiii) were willing to participate in the study and complete the questionnaire. 


\section{International Journal of Science and Research (IJSR) \\ ISSN (Online): 2319-7064}

Index Copernicus Value (2013): 6.14 | Impact Factor (2015): 6.391

Sample Size: 100-registered/ student nurses were administered the questionnairesat all the approved clinical areas of the hospital and also at nurse ees duty room and canteen.

Data analysis procedure: Data was analyzed using Statistical package for social sciences (SPSS) software. Data analysis procedure included basic descriptive statistics, and Pearson chi-Square Test.Basic descriptive statistics summarized the characteristics of the sample; Chi-square comparisons were performed to compare participants ${ }^{\text {ee }}$ knowledge of hand hygiene in the two hospitals.

\section{Results}

Table 1 about here ?

Majority of the respondents were females; there was no significant $\quad(p=0.079)$ variation in the gender of the respondents between the two facilities. Majority $(88 \%)$ of the respondents in the government hospital were registered nurses and a small number $(12 \%)$ of them were student nurses, however, all the respondents in the private facility were registered nurses. Almost half (46\%) the respondents in the government facility were either working in the department of surgery or the outpatient clinic, whereas, 50\% of the respondents in the private hospital were employed in the Intensive Care Unit [table 1].

Table 2 about here?

Majority $(97.9 \%)$ of the respondents in the private facility had received hand hygiene training in the past three years. Highly significant knowledge variationswas found concerning the main route of cross transmission $(28 \%$ and $77 \%)$ and the most frequent source of germs (4\% and 39\%). Knowledge about the most appropriate time duration to perform hand rubbing was found to be significantly low among public-sector nurses [table 2].

Table 3 about here?

There is significant variation in knowledge, concerning the correlation of performance of hand hygiene after a body fluid exposure $\left(100 \%\right.$ and $83 \%$ ) and exposure to patients ${ }^{\text {ee }}$ immediate surroundings $(0 \%$ and $18 \%)$ with the prevention of germ-transmission.

Table 4 about here?

As is evident from table 4, knowledge about the various hand hygiene actions for the prevention of germtransmission to the healthcare workers was not found to be significantly different in either of the study groups.

Table 5 about here?

Table 5 shows highly significant difference in the knowledge about the effectiveness of hand rubs and hand washing against the germs; about half of the corporate hospital nurses and only $5 \%$ of the public hospital nurses considered handrubbing to be less effective.

Table 6 about here?

Differences were highly significant concerning the correct hand hygiene method to be used in certain situations, such as: palpation of the abdomen $(20 \%$ and $62 \%)$, before giving an injection $(10 \%$ and $55 \%)$ and after removal of examination gloves $(10 \%$ and $44 \%)$ among the study groups [Table 6].

Table 7 about here?

Significant differences were found in the knowledge about the avoidance of certain germ-colonizing acts, like: wearing jewellery (100\% and $88 \%)$; damaged skin $(100 \%$ and $75 \%)$ and artificial fingernails (100 and 91\%) among the respondents of the government and corporate hospital.

\section{Discussion}

It will be a folly to underemphasize the role of hand hygiene in the prevention of $\mathrm{HCAI}^{19}$. Hand hygiene promotion is a complex issue, it is influenced by a number of factors such as: knowledge; awareness of personal and group performance; work-burden; and type, tolerance and accessibility of hand hygiene agents ${ }^{20}$.

Dearth of administrative support could be the reason why $50 \%$ of the nurses in the public hospital had not received any training in the field of hand hygiene in the last three years. Research shows that hand hygiene compliance is significantly higher in hospitals where management commitment and administrative support is forthcoming ${ }^{19}$.

Highly significant differences were found in the knowledge of nurses between the public and private facilities concerning the main route of transmission and the major source of germs, emphasizing the need for training among public sector nurses and improvement in the quality of training in the private hospital.

Performance of hand hygiene after touching any surface in the patient-zone and before contact with any surface in the health-care zone but without touching the patient ${ }^{21}$, cannot be an action that prevents the transmission of germs to the patient. This knowledge was significantly low among the respondents of the private hospital and could be attributed to poor awareness of the indications for hand hygiene and WHO's "my five moments for hand hygiene".

Nurses in the private hospital had significantly less knowledge of the fact that handrubs are more effective against germs, which is well corroborated by scientific literature ${ }^{19}$. Most of the nurses, in both the facilities, had a misconception that handrubbing caused more skin dryness, which is not true because the major cause of occupational hand dermatitis is handwashing with soap and water ${ }^{22}$.

Use of alcohol-based handrub is the preferred method for routine decontamination, especially in situations (like contact with intact skin, before insertion of invasive devices, after contact with inanimate objects) where hands are not visibly soiled ${ }^{23}$, but this knowledge was significantly low among nurses of the government hospital.

Regular use of hand cream is essential for keeping the skin hydrated but these moisturizing agents are not usually sterile and can get contaminated ${ }^{21}$. This knowledge was found to be significantly less among the nursing personnel of the private facility. 


\section{International Journal of Science and Research (IJSR) \\ ISSN (Online): 2319-7064}

Index Copernicus Value (2013): 6.14 | Impact Factor (2015): 6.391

\section{Conclusion}

This study highlights the need for a carefully planned educational programme, which provides accurate facts and disseminates hand hygiene guidelines ${ }^{21}$.Training programmes should be customized, keeping in mind the needs and skills of the target audience to facilitate learning. Follow-up programmes should also be introduced to constantly update the knowledge. However, education or training alone cannot ensure long-term behavior improvement and therefore $\mathrm{WHO}^{\mathrm{e}} \mathrm{S}$ multimodal strategy ${ }^{21}$ can be employed in both the corporate and public hospitals.

\section{Acknowledgement}

I would like to thank Dr. Malini R. Capoor for patiently guiding me through this study. I would also like to thank Dr. H.P. Singh, Mrs. ParamjitKaur, Mr. Dayanadha, MsNavneet and Mr. Gurinder for their invaluable support.

\section{Conflict of Interest: Nil}

\section{Source of Funding: Self}

Ethical Clearance: Not required

\section{References}

[1] Boyce J. Update on hand hygiene. Am J Infect Control 2013, 41:594-596.

[2] Squires J, Suh K, Liklater S, Bruce N, Gartke K, Graham I, Karovitch A, Read J, Roth V, Stockton K, Tibbo E, Woodhall K, Worthington J, Grimshaw J: Improving physician hand hygiene compliance using behavioural theories: a study protocol. Implement Sci 2013, 8:16.

[3] Pfoh E, Sydney D. Interventions to improve hand hygiene compliance: brief update review. In Making Health Care Safer 11: An Updated Critical Analysis of the Evidence for Patient Safety Practices. Edited by Shekelle PG, Wachter RM, Pronovost PJ. Rockville, MD: Evidence Report/Technology Assessment Number 211, Agency for Healthcare Research and Quality; 2013.

[4] Longtin Y, Sax H, Allegranzi B, Schneider F, Pittet D. "Videos in clinical medicine. Hand hygiene". The New England Journal of Medicine, vol. 364, article e24, 2011.

[5] Tibballs J. Teaching hospital medical staff to hand wash. Medical Journal of Australia. 1996; 164(7): 395398.

[6] Pittet D, Hugonnet S, Harbarth S, et al. Effectiveness of a hospital-wide programme to improve compliance with hand hygiene.The Lancet. 2000; 356 (9238): 13071312.

[7] Pittet, D. Infection control and quality health care in the new millennium. American Journal of Infection Control.2005; 33(5): 258-67. doi: 10.1016/j.ajic.2004.11.004

[8] Allegranzi, B, Gayet-Ageron A, Damani N, Bengaly L, McLaws ML, Moro ML,...Pittet, D. Global implementation of WHO's multimodal strategy for improvement of hand hygiene: a quasi-experimental study. The Lancet: Infectious Diseases, 2013; 13(10): 843-851. doi: 10.1016/S1473-3099(13)70163-4

[9] World Health Organisation (WHO): Report on the Burden of Endemic Health Care-Associated Infection Worldwide. Geneva: WHO; 2011.

[10]Baker GR, Norton PG, Flintoft V, Blais R, Brown A, Cox, J...Tamblyn R. The Canadian adverse events study: Incidence of adverse events among hospital patients in Canada. Canadian Medical Association Journal. 2004; 170(10): 1678-1686. doi:10.1053/cmaj.1040498

[11]Rickard NA. Hand hygiene: Promoting compliance among nurses and health workers. British Journal of Nursing.2004; 13: 404-410.

[12] Song X, Stockwell D, Floyd T, Short BL, Singh N. Improving hand hygiene compliance in health care workers: Strategies and impact on patient outcomes. American Journal of Infection Control. 2013; 41(10): 101-105. doi: 10.1016/j.ajic.2013.01.031

[13] Stone PS, Fuller C, Savage J, Cookson B, Hayward A, Cooper B,...Charlette, A. Evaluation of the national Cleanyourhands campaign to reduce Staphylococcus aureusbacteraemia and Clostridium difficile infection in hospitals in England and Wales by improved hand hygiene: four year, prospective, ecological, interrupted time series study. British Medical Journal.2012; 344, e3005. doi: 10.1136/bmj.e3005

[14] Buerhaus PI, Auerbach DI, Staiger DO. Recent trends in the registered nurse labor market in the U.S.: shortrun swings on top of long-term trends. Nursing Economics. 2007; 25(2): 59-66.

[15] Abualrub RF. Nursing shortage in Jordan: what is the solution? Journal of Professional Nursing.2007; 23(2): $117-120$.

[16] International Council of Nurses (2012). The ICN Code of Ethics for Nurses. Geneva: International Council of Nurses. Retrieved from: http://www.icn.ch/images/stories/documents/about/icnc ode_english.pdf

[17] Shinde MB, Mohite VR. A study to assess knowledge, attitude and practices of five moments of hand hygiene among nursing staff and students at a tertiary care hospital at Karad. International Journal of Science and Research. 2014;3(2):311-321.

[18] Chen YC, Sheng WH, Wang JT, Chang SC, Lin HC, Tien KL,... Tsai KS. Effectiveness and limitations of hand hygiene promotion on decreasing healthcareassociated infections. PLoS One.2011;6(11). doi: 10.1371/journal.pone. 0027163

[19] Jumaa PA. Hand hygiene: simple and complex. International Journal of Infectious Diseases. 2005; 9: 314.

[20] Pittet D, Simon A, Hugonnet S, Pessoa-Silva CL, Sauvan V, Pemeger TV. Hand hygiene among physicians: performance, beliefs and perceptions. Annals of Internal Medicine. 2004; 141(1): 1-8.

[21] WHO Guidelines for Hand Hygiene in Health Care (Advanced Draft). Geneva, World Health Organization, 2006.

[22]Kampf G, Loffler H. Prevention of irritant contact dermatitis among healthcare workers by using evidence- 


\section{International Journal of Science and Research (IJSR) \\ ISSN (Online): 2319-7064}

Index Copernicus Value (2013): 6.14 | Impact Factor (2015): 6.391

based hand hygiene practices: a review. Industrial

Health. 2007; 45: 645-652.

[23] Pittet D. Hand hygiene: impoved standards and practice for hospital care. Current Opinion in Infectious Diseases. 2003; 16: 327-335.

Table 1 Shows the Demographic characteristics of Nurses that participated in the study Total 100 nurses participated in the study

\begin{tabular}{|l|c|c|c|c|}
\hline Demographics & & Govt. Hospital (\%) & Pvt. Hospital (\%) & p-value \\
\hline Gender & Male & 0 & 6 & $0.079^{*}$ \\
& Female & 100 & 94 & $0.012^{*}$ \\
\hline Profession & Registered nurse & 88.05 & 100 & 0 \\
& Nursing student & 12.0 & 2 & $0.001^{* *}$ \\
& Internal medicine & 14 & 2 & \\
& Surgery & 26 & 50 & \\
& ICU & 6 & 18 & \\
& Mixed (medical/surgical) & 8 & 0 & \\
& Emergency & 0 & 2 & \\
& Obstetrics & 2 & 4 & \\
& Pediatrics & 0 & 14 & \\
& OPD & 20 & 24 & \\
& Others & 24 & & \\
\end{tabular}

*Not Significant, $* * \mathrm{p}<0.05$ (Significant)

Table 2: Distribution of responses according to various aspects of hand hygiene knowledge

\begin{tabular}{|c|c|c|c|c|}
\hline Question & Response & $\begin{array}{c}\text { Govt. Hospital } \\
\text { \% }\end{array}$ & Pvt. Hospital \% & p-value \\
\hline $\begin{array}{c}\text { Did you receive formal training in hand hygiene in the } \\
\text { last three years? }\end{array}$ & No & 50.0 & 2.1 & $<0.001^{* * *}$ \\
\hline $\begin{array}{c}\text { Do you routinely use alcohol-based handrub for hand } \\
\text { hygiene? }\end{array}$ & Yes & 100.0 & 100.0 & - \\
\hline $\begin{array}{c}\text { Which is the main route of cross-transmission of } \\
\text { potentially harmful germs between patients in a } \\
\text { health-care facility? }\end{array}$ & $\begin{array}{c}\text { Healthcare-workers } \\
\text { hands when not clean }\end{array}$ & 28.0 & 77.1 & $<0.001^{* * *}$ \\
\hline $\begin{array}{c}\text { What is the most frequent source of germs responsible } \\
\text { for healthcare-associated infections? }\end{array}$ & $\begin{array}{c}\text { Germs present on or } \\
\text { within the patient }\end{array}$ & 4.0 & 38.8 & $<0.001^{* * *}$ \\
\hline $\begin{array}{c}\text { What is the minimum time needed for alcohol-based } \\
\text { handrub to kill most germs on your hands? }\end{array}$ & 20 seconds & 16.7 & 47.9 & $<0.001^{* * *}$ \\
\hline
\end{tabular}

$* * \mathrm{p}<0.05$ (Significant); $* * * \mathrm{p}<0.001$ (Highly significant)

Table 3. Which of the following hand hygiene actions prevent transmission of germs to the patient?

\begin{tabular}{|c|c|c|c|}
\hline Hand hygiene actions & $\begin{array}{c}\text { Govt. } \\
\text { Hospital }\end{array}$ & Pvt. Hospital & p-value \\
\hline Before touching the patient (yes) & $50(100 \%)$ & $48(96 \%)$ & $0.153^{*}$ \\
\hline Immediately after a risk of body fluid exposure (yes) & $31(100 \%)$ & $35(83.3 \%)$ & $0.017 * *$ \\
\hline After exposure to the immediate surroundings of the patient $(\mathrm{no})$ & $0(0 \%)$ & $8(18.6 \%)$ & $0.011 * *$ \\
\hline Immediately before a clean or aseptic procedure (yes) & $31(100 \%)$ & $41(91.1 \%)$ & $0.088^{*}$ \\
\hline
\end{tabular}

*Not Significant, $* * \mathrm{p}<0.05$ (Significant)

Table 4: Which of the following hand hygiene actions prevent transmission of germs to the HCWs?

\begin{tabular}{|c|c|c|c|}
\hline Hand hygiene actions & Govt. Hospital & Pvt. Hospital & p-value \\
\hline After touching a patient (yes) & $50(100 \%)$ & $45(100 \%)$ & - \\
\hline Immediately after a risk of body fluid exposure (yes) & $31(100 \%)$ & $40(95.2 \%)$ & $0.218^{*}$ \\
\hline Immediately before a clean or aseptic procedure (no) & $0(0 \%)$ & $4(9.8 \%)$ & $0.074^{*}$ \\
\hline After exposure to patient"s simmediate surroundings (yes) & $31(96.8 \%)$ & $34(85 \%)$ & $0.099^{*}$ \\
\hline
\end{tabular}

*Not significant

Table 5. Distribution of responses according to the veracity of statements about alcohol-based handrub and handwashing

\begin{tabular}{|c|c|c|c|}
\hline Statements & Govt. Hospital & Pvt. Hospital & p-value \\
\hline Handrubbing is more rapid than hand washing (true) & $33(100 \%)$ & $43(97.7 \%)$ & $0.383^{* * *}$ \\
\hline Hand rubbing causes more skin dryness than handwashing (false) & $7(22.6 \%)$ & $9(20.5 \%)$ & $0.825^{* * *}$ \\
\hline Handrubbing is more effective against germs than handwashing (true) & $41(95.3 \%)$ & $26(56.5 \%)$ & $<0.001^{* *}$ \\
\hline Handwashing and handrubbing should be performed in a sequence (false) & $7(20 \%)$ & $11(26.8 \%)$ & $0.453^{* * *}$ \\
\hline
\end{tabular}

*Not significant; $* * * \mathrm{p}<0.001$ (Highly significant)

Table 6: Distribution of the responses according to the most accurate hand hygiene methods required in a particular situation

\begin{tabular}{|c|c|c|c|}
\hline Situation & Govt. Hospital & Pvt. Hospital & p-value \\
\hline Before palpation of the abdomen (rubbing) & $10(20 \%)$ & $31(62 \%)$ & $<0.001^{* * *}$ \\
\hline
\end{tabular}

\section{Volume 5 Issue 5, May 2016}




\section{International Journal of Science and Research (IJSR) \\ ISSN (Online): 2319-7064}

Index Copernicus Value (2013): 6.14 | Impact Factor (2015): 6.391

\begin{tabular}{|c|c|c|c|}
\hline Before giving an injection (rubbing) & $5(10 \%)$ & $27(55.1 \%)$ & $<0.001^{* * *}$ \\
\hline After emptying a bedpan (washing) & $36(72 \%)$ & $41(82 \%)$ & $0.097^{*}$ \\
\hline After removing examination gloves (rubbing/washing) & $5(10 \%)$ & $22(44 \%)$ & $<0.001^{* * *}$ \\
\hline After making a patient"s bed (rubbing) & $6(12 \%)$ & $13(26 \%)$ & $0.074^{*}$ \\
\hline After visible exposure to blood (washing) & $42(84 \%)$ & $38(76 \%)$ & $0.356^{*}$ \\
\hline
\end{tabular}

*Not significant; $* * * \mathrm{p}<0.001$ (Highly significant)

Table 7: Dirtribution of the reponsesaccording to the actions which should be prevented to decrease germ-colonization on hands

\begin{tabular}{|c|c|c|c|}
\hline Actions to be avoided & Govt. Hospital & Pvt. Hospital & p-value \\
\hline Wearing jewellery (yes) & $43(100 \%)$ & $4488 \%)$ & $0.019^{* *}$ \\
\hline Damaged skin (yes) & $34(100 \%)$ & $33(75 \%)$ & $0.002^{* *}$ \\
\hline Artificial fingernails (yes) & $43(100 \%)$ & $41(91.1 \%)$ & $0.045^{* *}$ \\
\hline Regular use of a handcream (no) & $24(75 \%)$ & $15(34.9 \%)$ & $0.001^{* *}$ \\
\hline
\end{tabular}

$* * \mathrm{p}<0.05$ (Significant)

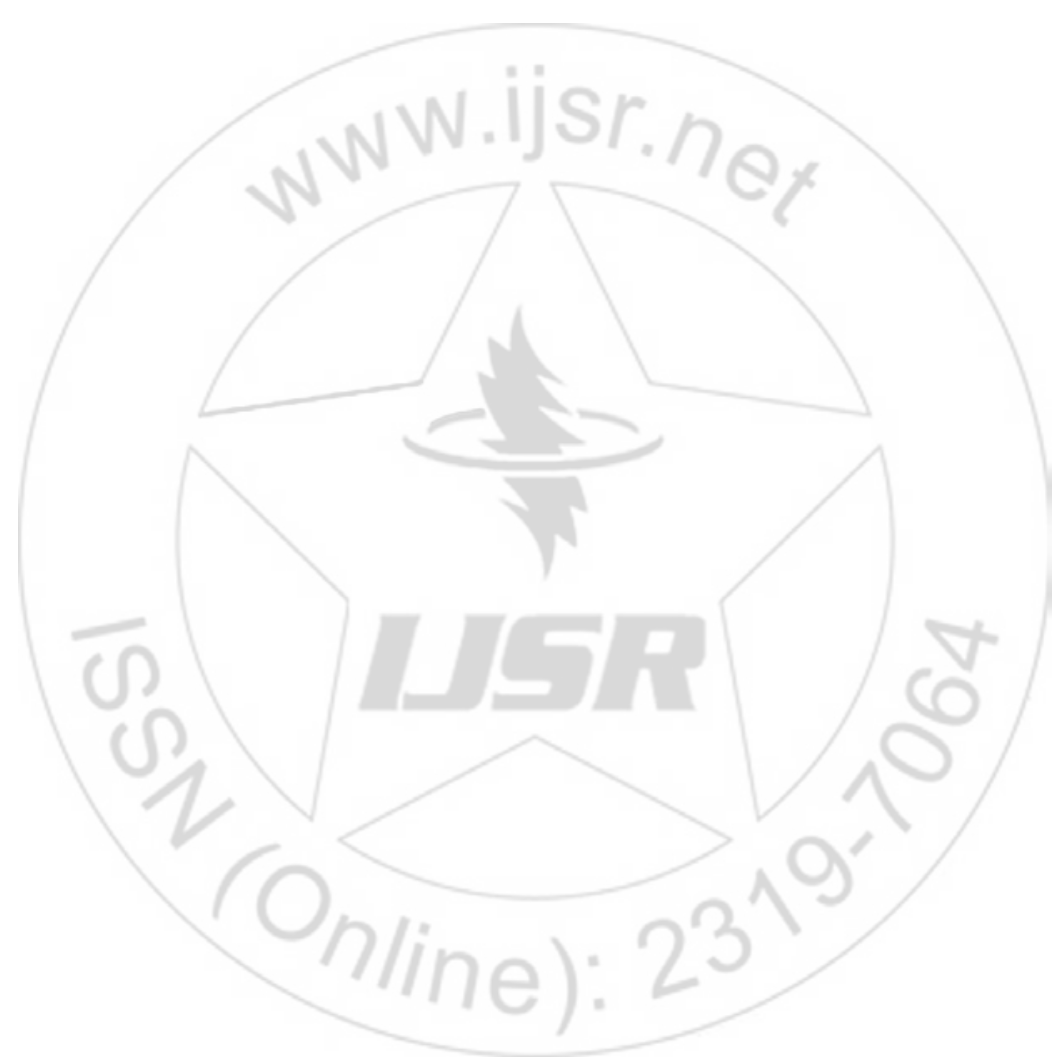

Volume 5 Issue 5, May 2016

www.ijsr.net 